KAUDERNI : Journal of Fisheries, Marine and Aquatic Science

https://jurnal.stplpalu.ac.id/index.php/kauderni/index

Volume 2, Nomor 2, (2020)

ISSN 2541-0571

https://doi.org/10.47384/kauderni.v2i2.47

\title{
PERTUMBUHAN DAN KELANGSUNGAN HIDUP IKAN BETOK (Anabas testudineus) YANG DIBERIKAN PAKAN KOMERSIAL DENGAN FREKUENSI BERBEDA
}

\author{
Rafli $^{1)^{*}}$, Nasmia $^{1)}$, Madinawati $^{1)}$, dan Samliok Ndobe ${ }^{1)}$ \\ ${ }^{1}$ Jurusan Akuakultur, Fakultas Peternakan dan Perikanan, Universitas Tadulako \\ Jl. Soekarno Hatta, Universitas Tadulako, Palu - Sulawesi Tengah 94118 \\ Email: raflipaparazie18@gmail.com
}

\begin{abstract}
This study aimed to determine the effect of commercial feeding (pellets) on the growth and viability of Betok fish (Anabas testudineus). The research was conducted at the Laboratory of Water Quality and Aquatic Biology, Faculty of Animal Husbandry and Fisheries, University of Tadulako Palu, from November to December 2019. This study was designed using a completely randomized design (CRD) with four treatments and five replications. Treatment $A$ (feeding $2 \times /$ day), $B$ (feeding $3 \times /$ day), $C$ (feeding $4 \times /$ day) and $D$ (feeding $5 \times /$ day). The results showed that feeding with different frequencies did not affect the growth in absolute weight and absolute length of Betok fish (Anabas testudineus). The growth of the absolute weight of Betokfish that was reared for one month ranged from 2.05-2.38 g, while the absolute length growth of the betok fish ranged from 0.345-0.42 $\mathrm{cm}$. The highest growth in absolute weight and the absolute length was found at the feeding frequency of $2 \times /$ day (A). The survival rate of Betok fish (Anabas testudineus) reared for one month is 100\%. During the research, water quality, it was still around the optimum range of betok fish growth.
\end{abstract}

Keywords: frequency of feeding, growth and survival, betok fish

\section{PENDAHULUAN}

Ikan betok (Anabas testudineus) adalah salah satu jenis ikan rawa yang berpotensi untuk dibudidayakan. Kendala yang dihadapi dalam pengembangan budidaya ikan betok adalah pertumbuhannya yang lambat karena untuk mencapai ukuran panjang 8-10 $\mathrm{cm}$ dan bobot 15-16 $\mathrm{g}$ memerlukan waktu 6-7 bulan (Ahmad dan Fauzi, 2010). Ikan betok termasuk komoditas ekonomis penting khususnya di daerah Kalimantan. Menurut Faturrahman (2011), harga ikan betok atau sering disebut juga ikan papuyu konsumsi berkisar Rp 40.000,00 sampai dengan $\mathrm{Rp} 70.000,00 / \mathrm{kg}$ dengan jangka pemeliharaan 6 sampai 9 bulan. Namun demikian, sebagian besar masih mengandalkan hasil penangkapan di alam sehingga hal ini cenderung mengakibatkan penurunan stok ikan betok di alam. Oleh karena itu, diperlukan kegiatan usaha budidaya untuk memenuhi kebutuhan konsumi masyarakat dan menjaga ikan tersebut agar tidak punah.

Menurut Froese dan Pauly (2019), secara morfologi ikan betok (Anabas testudineus) berbentuk fusiform dan pipih (laterally compressed); warna kehijauan sampai gelap, perut berwarna lebih mudah; garis-garis memanjang (longitudinal stripes) pada bagian bawah kepala; sisik berukuran besar dengan pola yang teratur, jumlah duri/jari sirip cukup bervariasi, misalnya 1620 pada sirip dorsal. Rukmini et al. (2013) menyebutkan bahwa pertumbuhan sirip larva betok sudah mulai tumbuh dan lengkap pada ukuran larva $>8,3 \mathrm{~mm}$. Gerigi mulai tumbuh pada panjang total larva $>5 \mathrm{~mm}$. Jacob (2005) mengemukakan bahwa bentuk (terutama rasio panjang/tinggi badan) dan warna tubuh A. testudineus dapat bervariasi antar populasi. Ikan betok bersifat biseksual, tidak 
KAUDERNI : Journal of Fisheries, Marine and Aquatic Science

https://jurnal.stplpalu.ac.id/index.php/kauderni/index

Volume 2, Nomor 2, (2020)

ISSN 2541-0571

https://doi.org/10.47384/kauderni.v2i2.47

terdapat perbedaan morfologi eksternal yang nyata antar jenis kelamin. Ikan betok sering disebut ikan pejalan (walking fish atau climbing perch). Keterampilan untuk berjalan jauh di darat sudah sangat di kenal, menggunakan ekor untuk bergerak, sirip perut, sirip dada, dan tutup insang yang keras digunakan untuk mendukung bobot badan (Ndobe et al. 2019). Menurut Akbar (2012a), sebenarnya tutup insang ikan betok berfungsi sebagai kaki tambahan waktu ikan ini berjalan di darat, tutup insang yang berduri ini di rentangkan untuk menjaga keseimbangan, sedangkan sirip dada dan sirip ekor mendorong untuk maju.

Ketersediaan pakan terutama pakan alami untuk mendukung kelangsungan hidup dan pertumbuhan larva ikan merupakan faktor penting yang harus terpenuhi baik kualitas maupun kuantitasnya tetapi dibutuhkan pula pakan buatan yang menunjang pemberian pakan alami (Yulintine, 2012). Berdasarkan penelitian Rukmini et al. (2013) konsumsi jenis plankton ikan betok di perairan alami adalah Coconeis sp. dan Keratella sp. pada semua umur larva (3-31 hari).

Penelitian juga pernah dilakukan Rahmi et al. (2016), laju pertumbuhan bobot ikan betok dengan frekuensi pemberian pakan sebanyak 5 kali perhari yang diberi pakan cacing sutera berkisar antara 13,8519,35\% dengan kelangsungan hidup berkisar antara 39-88,67\%. Penelitian Putra et al. (2017), laju pertumbuhan harian ikan manfish (Pterophyllum scalare) yang diberikan pakan sebanyak 3 kali sehari berkisar antara 0,61-3,05 g, dengan kelangsungan hidup $100 \%$. Sedangkan pada penelitian yang dilakukan Deftari et al. (2015), pada ikan gurame dengan frekuensi pemberian pakan sebanyak 5 kali perhari bobot mutlaknya sebesar 2,64 g. Sementara Miranti et al. (2017), mengemukakan laju pertumbuhan bobot ikan betok dengan frekuensi pemberian pakan sebanyak 5 kali perhari berkisar antara $0,06-0,50 \mathrm{~g}$.

Informasi tentang frekuensi pemberian pakan pada benih ikan betok yang diberi pakan komersial (pelet) hingga saat ini belum ada. Oleh karena itu, perlu dilakukan penelitian mengenai frekuensi pakan pada benih ikan betok, sehingga pakan yang diberikan lebih bermanfaat dengan baik untuk meningkatkan kelangsungan hidup dan pertumbuhan benih ikan betok.

\section{METODE PENELITIAN Waktu dan Tempat Penelitian}

Penelitian dilaksanakan pada bulan November hingga Desember 2019, di Laboratorium Akuakultur, Fakultas Peternakan dan Perikanan, Universitas Tadulako, Palu, Sulawesi Tengah.

\section{Organisme Uji}

Organisme uji adalah ikan betok berukuran 7,225-8,35 cm dengan bobot 6,74$8,900 \mathrm{~g}$, yang berasal dari pembudidaya ikan di Desa Maranata, Kabupaten Sigi, Sulawesi Tengah. Pengangkutan organisme uji dilakukan dengan memasukkan ikan betok ke dalam kantongan plastik yang diberi oksigen lalu dimuat dalam Styrofoam yang di dalamnya disimpan beberapa bungkus kecil es untuk menjaga suhu agar tetap dalam kondisi normal lalu diangkut menggunakan sepeda motor dari Desa Maranata menuju Laboratorium Akuakultur, Universitas Tadulako, Palu.

\section{Desain Penelitian}

Penelitian didesain dengan menggunakan rancangan acak lengkap (RAL) menggunakan 4 perlakuan dengan masing-masing 5 ulangan, sehingga banyaknya satuan percobaan adalah 20 unit. Perlakuan A: pemberian pakan $2 \times /$ hari, B: pemberian pakan $3 \times /$ hari, C: pemberian pakan $4 \times /$ hari dan $\mathrm{D}$ : pemberian pakan $5 \times /$ hari.

\section{Peneliharaan Organisme Uji}

Proses pemeliharaan pertama-tama dilakukan aklimatisasi ikan terlebih dahulu sebelum penebaran. Ikan betok akan ditebar dengan padat tebar 1 ekor/2 liter, ikan yang digunakan sebanyak 80 ekor dan ditebar 4 ekor per wadah yang berisi air pada masingmasing wadah sebanyak 8 liter dan dipelihara selama satu (1) bulan. 
KAUDERNI : Journal of Fisheries, Marine and Aquatic Science

https://jurnal.stplpalu.ac.id/index.php/kauderni/index

Volume 2, Nomor 2, (2020)

ISSN 2541-0571

https://doi.org/10.47384/kauderni.v2i2.47

\section{Perhitungan dan Analisis Data}

Pertumbuhan mutlak dan panjang mutlak yang diperoleh selama penelitian dianalisis menggunakan analisis ragam (ANOVA). Jika terdapat pengaruh nyata dari perlakuan, maka dilanjutkan dengan uji beda nyata terkecil (BNT). Data dianalisis dengan menggunakan Mini Tab (16) dan Microsoft Exel (2007) sedangkan data kelangsungan hidup dan kualitas air dianalisis secara deskriptif menggunakan tabel dan grafik.

\section{HASIL DAN PEMBAHASAN Pertumbuhan Bobot Mutlak Ikan Betok (Anabas testudineus)}

Berdasarkan hasil analisis ragam (ANOVA) menunjukkan bahwa pemberian pakan dengan frekuensi berbeda, tidak berpengaruh nyata $(\mathrm{P}>0,05)$ terhadap pertumbuhan bobot mutlak ikan betok. Pertumbuhan bobot mutlak ikan betok yang dipelihara selama satu bulan berkisar antara 2,05-2,38 g (Gambar 1).

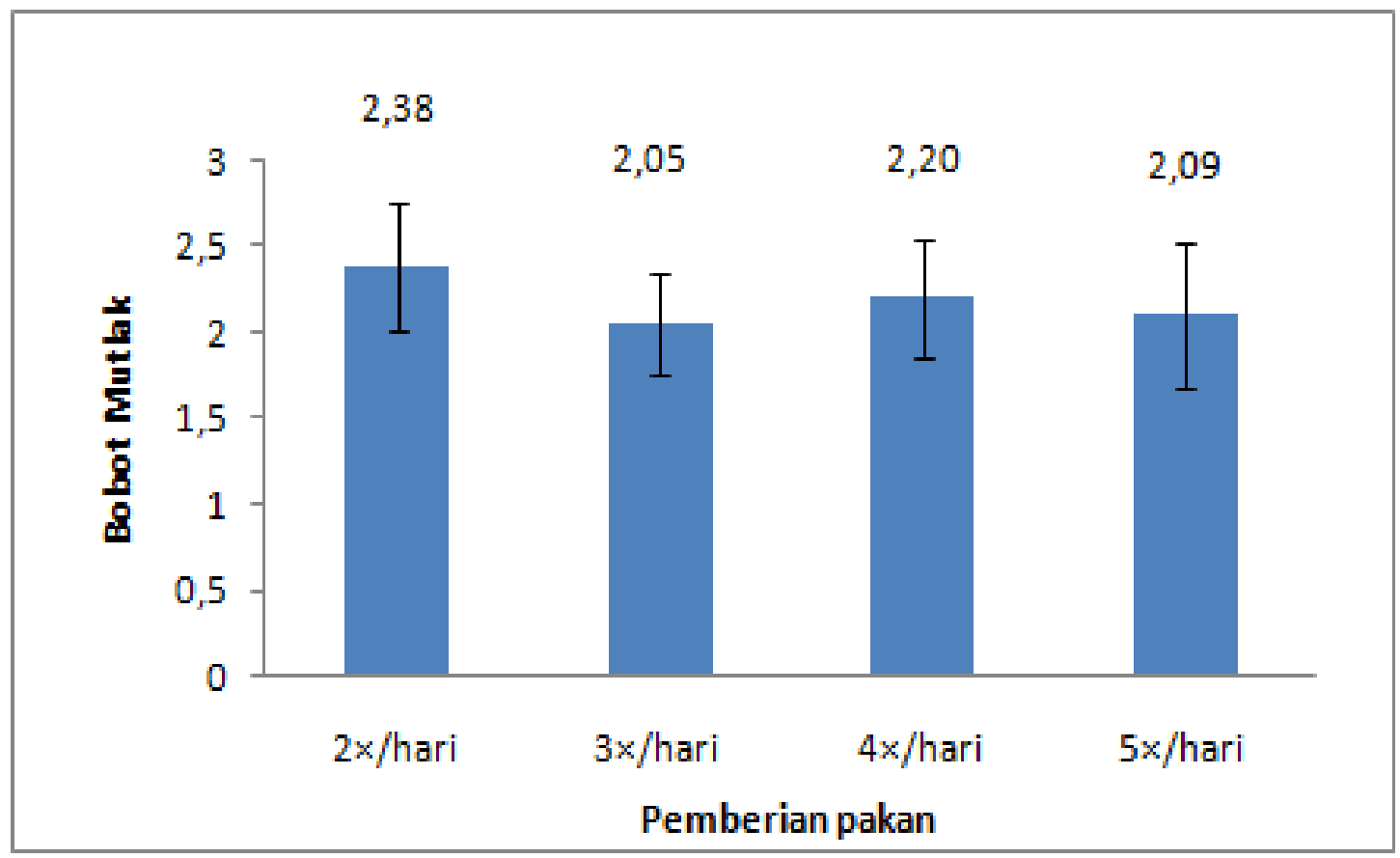

Gambar 1. Pertumbuhan bobot mutlak ikan betok (Anabas testudineus) selama pemeliharaan.

Hasil pengamatan selama satu bulan saat melakukan penelitian didapatkan pertumbuhan ikan betok cukup lambat. Akbar (2012b) menyatakan bahwa kendala utama dalam pengembangan budidaya ikan betok yaitu laju pertumbuhan ikan betok yang cukup lambat, dimana untuk mencapai ukuran kosumsi (75/100 g) diperlukan waktu pemeliharaan selama satu tahun atau lebih.

\section{Pertumbuhan Panjang Mutlak Ikan Betok (Anabas testudineus)}

Berdasarkan hasil analisis ragam (ANOVA) pada selang kepercayaan 95\% menunjukkan bahwa pemberian pakan dengan frekuensi berbeda, tidak berpengaruh nyata $(\mathrm{P}>0,05)$ terhadap panjang mutlak ikan betok. Pertumbuhan panjang mutlak ikan betok (Anabas testudineus) yang dipelihara selama satu bulan berkisar antara 0,345-0,42 $\mathrm{cm}$. 


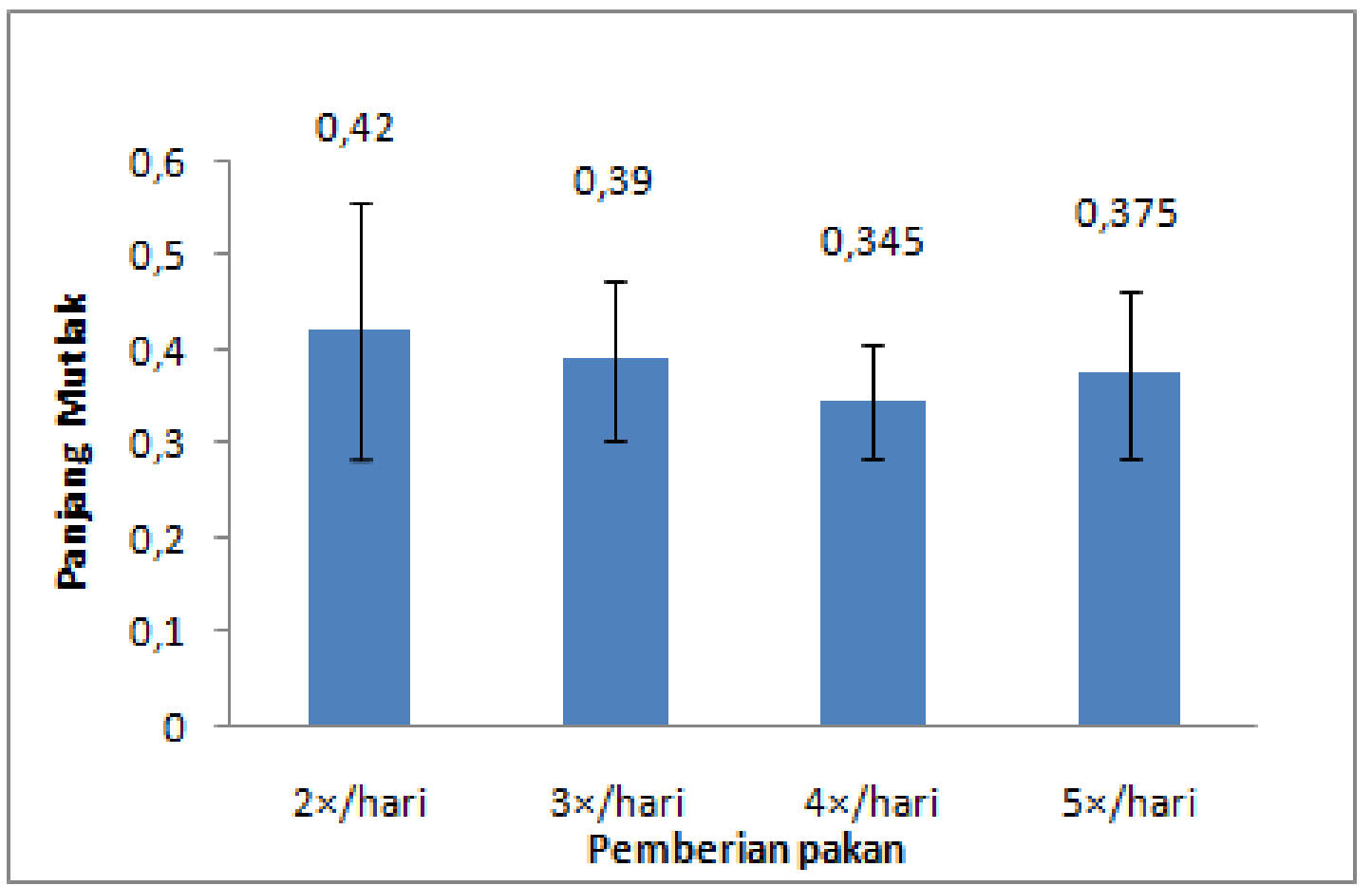

Gambar 2. Panjang mutlak ikan betok (Anabas testudineus) selama pemeliharaan.

Pertumbuhan panjang mutlak ikan betok pada perlakuan A (2 kali pemberian pakan) yaitu $0,42 \mathrm{~cm}$, lebih tinggi dibandingkan dari perlakuan lainnya. Hal ini diduga berkaitan dengan konsentrasi amonia yang lebih rendah pada perlakuan A, sehingga pertumbuhan ikan betok lebih optimal dari perlakuan lainnya. Hasil tersebut menunjukkan bahwa amonia dapat menghambat pertumbuhan ikan, akibat gangguan terhadap proses metabolisme tubuh. Hargreaves dan Kucuk (2001) menjelaskan bahwa akumulasi amonia menyebabkan pertumbuhan ikan menurun karena paparan amonia menyebabkan penurunan nafsu makan ikan dan mengurangi tingkat kecernaan pakan yang dikonsumsi.

\section{Kelangsungan Hidup Ikan Betok (Anabas testudineus)}

Kelangsungan hidup ikan betok pada semua perlakuan $100 \%$. Tingkat kelangsungan hidup yang tinggi karena ikan betok ini merupakan salah satu ikan air tawar yang toleran terhadap kondisi lingkungan tempat hidupnya dan juga termasuk jenis ikan yang tahan terhadap penyakit serta mempunyai alat pernapasan tambahan (labirin) sehingga mampu bertahan hidup walaupun kondisi oksigen terlarut di perairan tempat hidupnya rendah. Syulfia et al. (2016) menyatakan bahwa kelangsungan hidup ikan dipengaruhi oleh faktor internal dan eksternal, dimana faktor internal adalah resistensi terhadap penyakit, pakan dan umur. Sedangkan faktor eksternal adalah padat tebar, penyakit, dan kualitas air.

\section{Parameter Kualitas Air}

Parameter kualitas air media budidaya ikan betok yang diukur selama penelitian meliputi suhu, $\mathrm{pH}$, oksigen terlarut (DO) dan amoniak (Tabel 1).

Tabel 1. Parameter kualitas air pada media budidaya ikan betok

\begin{tabular}{cccccc}
\multirow{2}{*}{ No. } & \multirow{2}{*}{ Perlakuan } & \multicolumn{4}{c}{ Parameter kualitas air } \\
\cline { 3 - 6 } & & Suhu $\left({ }^{\circ} \mathrm{C}\right)$ & $\mathrm{pH}$ & $\mathrm{DO}(\mathrm{ppm})$ & $\begin{array}{c}\text { Amoniak } \\
\mathrm{mg} / \mathrm{L}\end{array}$ \\
\hline 1. & $\mathrm{A}$ & $26,7-29,2$ & $7-8$ & $4,6-7,2$ & $0,016-0,021$ \\
2. & $\mathrm{B}$ & $26,7-29,3$ & $7-8$ & $4,5-7,2$ & $0,020-0,021$ \\
3. & $\mathrm{C}$ & $26,7-29,5$ & $7-8$ & $5-7,2$ & $0,020-0,021$ \\
4. & $\mathrm{D}$ & $26,9-29,2$ & $7-8$ & $5,2-7,2$ & $0,021-0,024$ \\
\hline
\end{tabular}

Kisaran suhu, $\mathrm{pH}$, dan DO cenderung sama pada setiap perlakuan yaitu suhu berkisar antara $26,7-29,5^{\circ} \mathrm{C}, \mathrm{pH}$ 7-8, oksigen 
KAUDERNI : Journal of Fisheries, Marine and Aquatic Science

https://jurnal.stplpalu.ac.id/index.php/kauderni/index

Volume 2, Nomor 2, (2020)

ISSN 2541-0571

https://doi.org/10.47384/kauderni.v2i2.47

terlarut (DO) berkisar antara 4,5-7,2 ppm dan amoniak berkisar 0,016-0,024 $\mathrm{mg} / \mathrm{L}$. Tabel 1 menunjukkan bahwa kisaran semua parameter kualitas air yang diukur masih pada batas optimal pertumbuhan ikan betok.

\section{PENUTUP}

Pemberian pakan dengan frekuensi berbeda, tidak berpengaruh nyata $(\mathrm{P}>0,05)$ terhadap pertumbuhan mutlak dan panjang mutlak ikan betok (Anabas testudineus). Pertumbuhan bobot mutlak tertinggi dicapai pada perlakuan pemberian pakan $2 \mathrm{kali} / \mathrm{hari}$, sedangkan nilai pertumbuhan bobot mutlak terendah terdapat pada perlakuan pemberian pakan 3 kali/hari. Tingkat kelangsungan hidup $100 \%$.

\section{REFERENSI}

Ahmad, M dan Fauzi. 2010. Percobaan Pemijahan Ikan Puyu (Anabas testudienus). Jurnal Perikanan dan Kelautan. 15(1): 16-24

Akbar, J. 2012a. Ikan Betok Budidaya dan Peluang Bisnis. Eja Publisher, Yogyakarta.

Akbar, J. 2012b. Pertumbuhan dan kelangsungan hidup ikan betok (Anabas testudineus) yang dipelihara pada salinitas berbeda. Bioscientiae. 9 (2): $1-8$.

Deftari, P., H. Syandri dan Azrita. 2015. Perbedaan Frekuensi Pemberian Pakan Tubifex sp Terhadap Sintasan dan Pertumbuhan Benih Ikan Gurame (Osphronemous goramy Lac), Kumpulan Artikel Penelitian Mahasiswa S1 Program Studi BDP FPIK UBH. 8(1): 1-13.

Faturrahman. 2011. Investasi Potensial Menyemai Benih Papuyu. Layuh, Kabupaten Hulu Tengah, Kalimantan Selatan.

http://kalsel.antaranews.com/berita/37 74/investasi-potensial-menyemaibibitpapuyu. Diakses tanggal 8 Desember 2017.

Froese, R. and D. Pauly. 2019. FishBase. http://www.fishbase.org/summary/An bas-testudineus.html. Diakses tanggal 6 November 2020.

Hargreaves, J. A. and S. Kucuk. 2001. Effects Of Diel Un-Ionized Ammonia Fluctuation on Juvenile Hybrid Striped Bass, Channel Catfish, and Blue Tilapia. Aquaculture. 195: 163-181.

Jacob, P. K. 2005. Studies on some Aspects of Reproduction of Female Anabas testudineus (Bloch). PhD Thesis. Cochin University of Science and Technology, India.

Miranti, F., M. Muslim dan Y. Yulisman. 2017. Pertumbuhan dan Kelangsungan Hidup Larva Ikan Betok (Anabas testudineus) yang Diberi Pencahayaan dengan Lama Waktu Berbeda. Jurnal Akuakultur Rawa Indonesia. 5(1): 3344.

Ndobe, S., Rusaini, dan A. Masyahoro. 2019. Karakteristik Bioekologi Ikan Betok (Anabas testudineus) di Perairan Umum Kabupaten Sigi, Sulawesi Tengah. Laporan Akhir Penelitian DIPA. Fakultas Peternakan dan Perikanan, Universitas Tadulako, Palu.

Putra, A.K., F.S. Mumpuni dan Rosmawati. 2017. Pengaruh Pemberian Pakan Alami Yang Berbeda Terhadap Pertumbuhan dan Kelangsungan Hidup Benih Ikan Maanvis (Pterophyllum scalare). Jurnal Mina Sains. 3(1): 30-38.

Rahmi, I., Y. Yulisman dan M. Muslim. 2016. Kelangsugan Hidup dan Pertumbuhan Larva Ikan Betok (Anabas testudineus) yang diberi Cacing Sutera Dikombinasi dengan pakan Buatan. Jurnal Akuakultur Rawa Indonesia. 4(2): 128-139.

Rukmini, D. Marsoedi, Arfiati dan A. Mursyid. 2013. Jenis Pakan Alami Larva ikan Betok (Anabas testudineus Bloch) Di perairan Rawa Monoton Danau Bangkau, Kalimantan Selatan. BAWAL. 5(3): 181-188.

Syulfia R, P. Iskandar dan Rusliandi. 2016. Pertumbuhan dan Kelulushidupan Ikan Betok (Anabas testudineus) Dengan Padat Tebar Berbeda. Jurnal online 
KAUDERNI : Journal of Fisheries, Marine and Aquatic Science

https://jurnal.stplpalu.ac.id/index.php/kauderni/index

Volume 2, Nomor 2, (2020)

ISSN 2541-0571

https://doi.org/10.47384/kauderni.v2i2.47

mahasiswa Fakultas Perikanan dan Ilmu Kelautan. 3(1): 1-14.

Yulintine. 2012. Upaya Peningkatan

Kelangsungan Hidup Larva Ikan

Betok, Anabas testudineus Bloch

Melalui Studi Ontogeni Sistem

Pencernaan, Kemampuan Biosintesis

Hufa dan Pengkayaan Asam Lemak

Esensial. Disertasi. Institut Pertanian

Bogor, Bogor. 